\title{
The Use and Effects of Smartphones in Higher Education
}

\author{
https://doi.org/10.3991/ijim.v11i6.7453 \\ Hejab Ma'azer Al Fawareh( ${ }^{\varpi}$, Shaidah Jusoh \\ Northern Border University, Rafha, Saudi Arabia \\ Hejab.al-fawareh@nbu.edu.sa
}

\begin{abstract}
The purpose of this study is to investigate the use and effects of smartphones on academic staffs at a university level, especially in the Kingdom of Saudi Arabia. We conducted a survey study using questionnaires. The questionnaires were randomly distributed to 66 academic staffs who own a smartphone at the Northern Border University. This study discovers the smartphone had replaced a computer, and an email application was mostly used. The academic staffs also had utilized smartphone as a means for knowledge sharing. Social media applications were greatly used in teaching and learning. Despite the benefits of smartphone use, academic staffs had been negatively affected. This study also reveals that having a smartphone diverted academic staffs' focus at work, created "check habits", and an artificial relationship; more than $90 \%$ of the respondents admitted that they put their smartphone besides their bed before sleep, and $61.41 \%$ of them claimed that they had the feelings of incompleteness whenever smartphones were not with them.
\end{abstract}

Keywords - the use of smartphones, smartphones in teaching, effects of smartphones

\section{Introduction}

Nowadays, smartphones have become a part of every person life. People around the world have adopted this new and exciting technology as one of the most important required facility in their everyday life. A variety of smartphones applications is available to be used in a wider range of usage situations. It is no doubt a smartphone is a new gadget which has a capability to change people lives. Smartphones are used to replace digital cameras, watches, video recorders, and many more. Having a smartphone is like having a tiny computer in a pocket. With the advancement of the Internet technologies and its applications, smartphones are not only used for making phone calls but also for internet usage such as sending and receiving emails, chatting, sharing photos and documents, reading news, browsing the Internet, and online selling and buying. The dramatic growth of smartphone users has also increased the growth of social media users.

According to the Google's latest study, Australia, the United Kingdom (UK), Sweden, Norway, Saudi Arabia and the United Arab Emirates (UAE) all boast smartphone adoption rates above 50\%. All smartphones are equipped or ready for social media applications like Facebook, Twitter, Wikipedia, YouTube, WhatsApp, 
Telegram, and Instagram. These applications are characterized by social interaction, content sharing, and collective intelligence [1]. A research survey has shown that Americans spent 7.6 hours a month using social media, with the majority of individuals accessing social media through their smartphones [2].

Many studies such as $[3,4,5,6,7]$ have been conducted on assessing the use and effects of smartphones especially for learning purposes. For example, reference [3] and [4] reported on the nature of students' use of smartphones, as well as their attitudes towards utilizing smartphones for educational use, while $[5,6,7]$ reported that smartphones have negatively effects on a learning process.

Despite there has been a numerous research work on how smartphones are being used in a higher education, the great focus was given on student's perspectives. The purpose of this exploratory study is to have a better understanding of the use and effects of smartphones on academic staffs. This paper is organized as follows. Section 2 presents a related study and section 3 presents materials and method methods. Data and result analysis are presented in section 4, and the study is concluded in section 5 .

\section{Related Study}

With the help of mobile users, smartphones have become a very popular and desirable device. In the year of 2008, smartphone industries welcomed a new operating system called Android, introduced by Google. The concepts of smartphone applications came around at the same time when the first smartphones were released. Since then, many applications to run on an Android operating system have been developed by programmers around the world. The popularity of smartphone is very encouraging.

The dramatic increase in smartphone use in the Middle East has also affected consumers in this region to use their smartphones to engage with online and offline advertisements. For example, more than $3 / 4$ of smartphone users in Egypt have performed a mobile search after seeing an ad such as a TV commercial offline. In spite of only half look at the first page of search results on their phones, more than $90 \%$ of smartphone users in Egypt, Saudi Arabia, and UAE notice mobile advertising when they are surfing the mobile web. A recent study examining the state of the social media in Saudi Arabia noted a remarkable increase with the use mobile technologies such as smartphones to access various social media accounts. It was a sharp increase in the number of WhatsApp, Facebook, Google+, Twitter, Instagram users while Linkedin still stays behind. As of September 2015, WhatsApp had a user base of up to 900 million [2] making it the most globally popular messaging application in Saudi Arabia.

The use of smartphones in academic community has been studied by $[3,5,6,7,8.9,10,11,12]$, For example, [8] has conducted a study on 30 teaching staffs and 40 students which were randomly selected. Their findings show that $84 \%$ of the teaching staffs used their smartphones to access the Internet. They also reported that $100 \%$ of the teaching staffs use phone calls and text messages for communicating with colleagues on academic issues or alerting students. Among the 25 teaching staffs that have an internet access through their phones, $76 \%$ mentioned downloading schol- 
arly materials through their mobile phones. As stated in [11], social media sites such as Facebook and Twitter have continued to gain popularity among students on campuses. Students normally used their smartphones to access the sites. These social media sites allow students and teachers to share and communicate in any particular topics. Consequently, a study conducted by [12], presented results that smartphones are "habit forming"; people who owned a smartphone developed 'check habits', which they frequently check on one or more applications such as email or social media sites. Furthermore, according to [13], there are significant relationships between smartphone intrusion and stress levels which have contributed a significant negative relationship between smartphone and work-life balance.

\section{$3 \quad$ Materials and Method}

Survey questionnaires were randomly distributed to academic staffs of the Northern Border University, Saudi Arabia at Rafha Branch. The survey questionnaire consists of 2 parts. The first part consists of questions related to demographic data such as gender, age group, employment rank, the highest academic achievement and a question whether she/he owns a smartphone. The second part consists of questions which focus on regular usage of smartphones. Multiples choice and multiple selection questions are employed. The study is guided by the following research questions (RQs).

RQ1: How smartphone is being used?

RQ2: What types of applications are useful for completing job assignments?

RQ3: Does smartphone help academic staffs to complete job assignments faster?

RQ4: Does smartphone support knowledge sharing among academic staffs

RQ5: How smartphones have influenced academic staffs?

RQ6: Does smartphone give a negative impact to academic staffs at a workplace?

RQ7: Does smartphone create imbalance attention between job and family?

\section{$4 \quad$ Data and Result Analysis}

In this study, we managed to collect data from 66 academic staffs who own smartphones. Of the surveyed academic staffs, 33.33\% $(n=22 / 66)$ are females and $66.67 \%(n=44 / 66)$ are males. Fig. 1 shows the distribution percentage of academic achievement among surveyed academic staffs, where $71.21 \%$ of them are master degree holders and the majority of the respondents are in the age range of 30-39 years.

To answer RQ1, participants were asked to make multiple selections (see Table 2) on a smartphone as a device and how it is used for teaching purposes (Table 3). Result analysis shows the highest percentage of using a smartphone as a mobile computer, followed by a digital camera, and a watch. The use of smartphone as a scanner takes the least score. 
For teaching purposes, $90.76 \%$ of respondents have been using smartphones for supervising project' students through social media applications. However, only half of the respondents are willing to solve students' problems through call or messaging applications. The least score was using smartphones for displaying students ' grades.

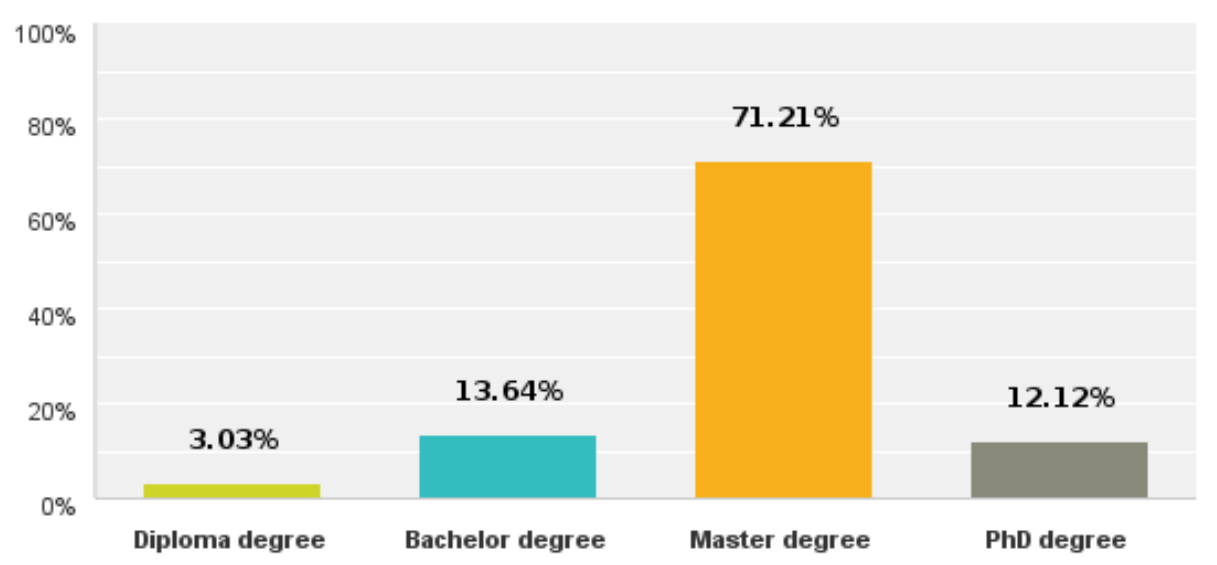

Fig. 1. Percentage of respondents according to academic achievement

Table 1. Age group of academic staffs

\begin{tabular}{|l|c|}
\hline \multicolumn{1}{|c|}{ Answer Options } & Response \\
\hline $20-29$ years & $23.44 \%$ \\
\hline $30-39$ years & $54.69 \%$ \\
\hline $40-49$ years & $20.31 \%$ \\
\hline $50-59$ years & $1.56 \%$ \\
\hline
\end{tabular}

Table 2. A smartphone as a device

\begin{tabular}{|l|c|}
\hline \multicolumn{1}{|c|}{ Answer Options } & Response Percentage \\
\hline A mobile computer (to read/send email, using internet) & $92.86 \%$ \\
\hline A digital camera (take photos and videos) & $82.14 \%$ \\
\hline A watch (time) & $76.79 \%$ \\
\hline A storage (store documents) & $64.29 \%$ \\
\hline A scanner (scanning documents) & $37.50 \%$ \\
\hline
\end{tabular}

Table 3. Teaching purposes

\begin{tabular}{|l|c|}
\hline \multicolumn{1}{|c|}{ Answer Options } & Response \\
\hline Supervising students through social media applications & $90.76 \%$ \\
\hline Accessing to teaching materials online & $87.79 \%$ \\
\hline Solving students problems through call or messaging applications & $49.84 \%$ \\
\hline Displaying student grades online & $33.21 \%$ \\
\hline
\end{tabular}


In order to study RQ2, we have listed a list of smartphone applications which can be used for completing job assignments. Participants were asked to make multiple selections from a list of smartphone applications. Figure 2 shows that an email application has the highest score, $(89.29 \%$ ), followed by Web access at $71.43 \%$. Only $32.14 \%$ of the respondents have used File reader to complete their job assignments.

Participants were also asked if smartphone can help them to complete their job faster (RQ3). Their responses were analyzed, and illustrated as in Fig. 3. The result of data analysis reveals that only $42.86 \%$ of the participants strongly agree and agree that by using a smartphone they can complete their job's assignment faster (see Figure 3 ). About $28.57 \%$ of participants feel it is neutral. This result indicates that about $50 \%$ of smartphone users do not feel that smartphones are able to help them to complete their job faster. Although smartphone applications may help academic staffs to complete their job assignments, but smartphones cannot be a device to help academic staffs to complete their job faster.

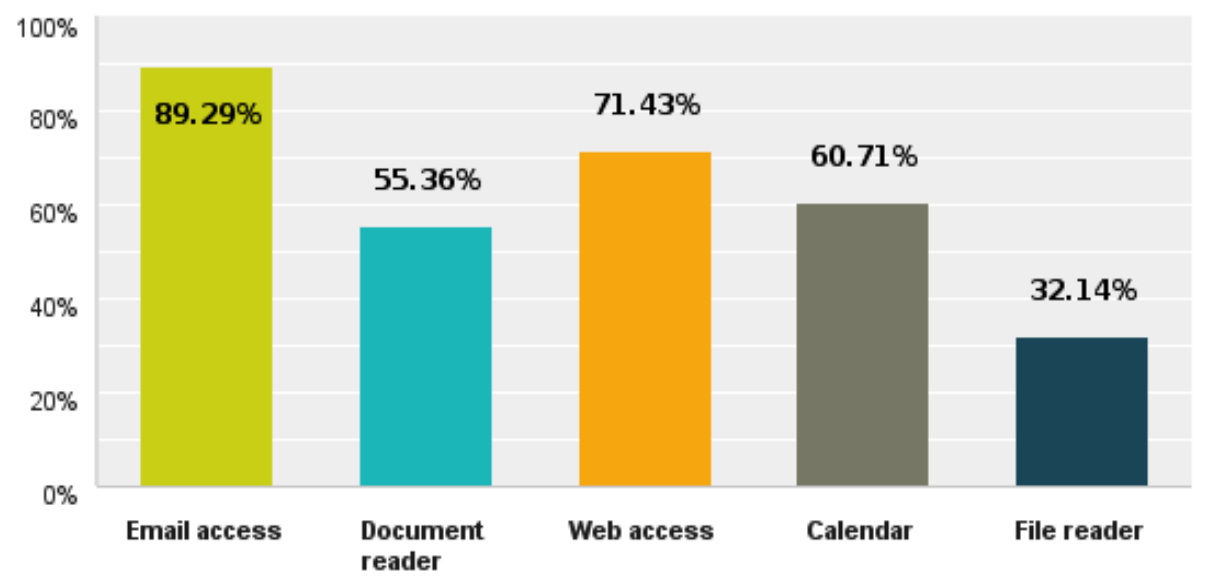

Fig. 2. The use of smartphone applications.

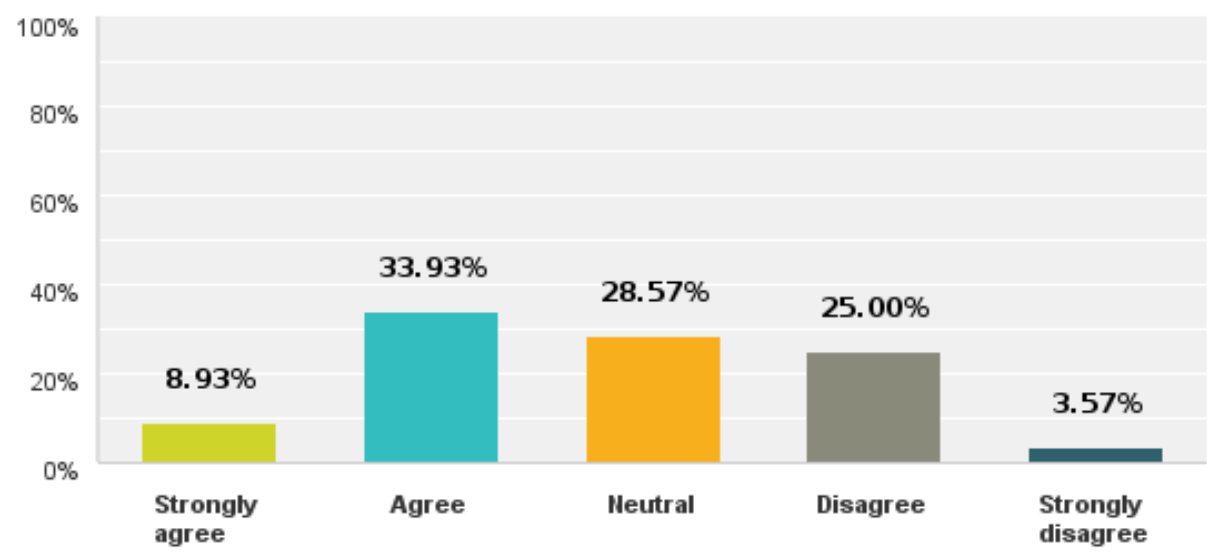

Fig. 3. . Smartphones as a means for completing job assignments faster 
This research also explores whether academic staffs utilize their smartphones as a means of for knowledge sharing (RQ4). Result analysis shows that $14.04 \%$ of respondents always and $71.93 \%$ of respondents sometimes use smartphones as a means for knowledge sharing (see Fig. 4). It is no doubt that smartphones is a means for knowledge sharing.

This study also explores to what extend does smartphone have influence on personal life (RQ5). Four questions were asked as shown in Table 4. Data analysis shows that $60 \%$ of the respondents put smartphones besides their bed before sleep and almost $40 \%$ of the respondents checked their smartphones as soon as they open their eyes. Results show that only $7.27 \%$ of the participants never put their smartphones besides their bed. Furthermore, only 10.71\% never check their smartphones first as soon as they open their eyes from sleep. Results reveal that $70.18 \%$ participants sometimes stop whatever they are doing whenever they hear a notification from their smartphones. The "check habit" behavior demonstrated that academic staffs are not different than other group of smartphone users as were discussed by [7].

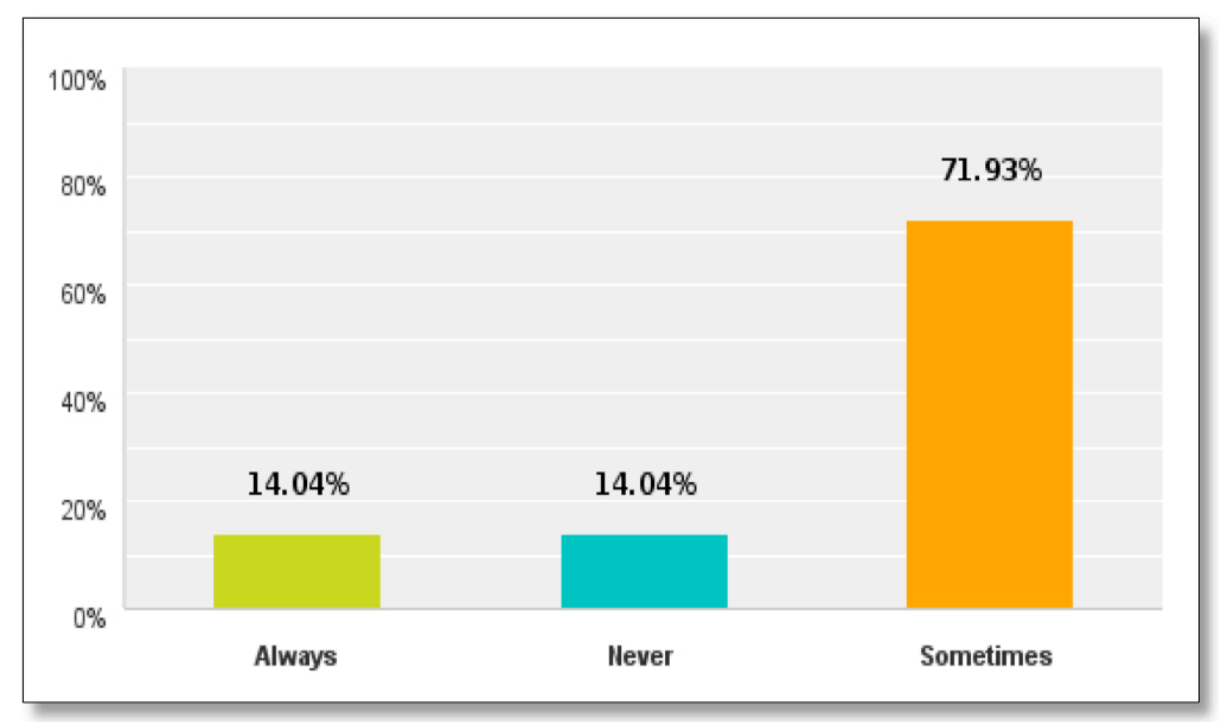

Fig. 4. Smartphones as a means for knowledge sharing

Table 4. Effects of smartphones on personal life

\begin{tabular}{|l|c|c|c|}
\hline \multicolumn{1}{|c|}{ Questions } & \multicolumn{2}{c|}{ Response Percentage } \\
\cline { 2 - 4 } & Always & Sometimes & Never \\
\hline When I need to sleep, I will put my smartphone beside me. & 60.00 & 32.73 & 7.27 \\
\hline $\begin{array}{l}\text { When I open my eyes, the first thing I check is what is on my } \\
\text { smartphone. }\end{array}$ & 37.5 & 51.79 & 10.71 \\
\hline $\begin{array}{l}\text { I would stop whatever I am doing whenever I hear a notifica- } \\
\text { tion from my smartphone. }\end{array}$ & 8.77 & 70.18 & 21.05 \\
\hline
\end{tabular}


Respondents were also asked for a response to a statement "I feel my life is incomplete when my smartphone is not with me" with options of strongly agree, neutral, disagree, and strongly disagree. Data analysis showed that $61.41 \%$ of the respondents were strongly agreed and agreed for the feelings of incompleteness whenever smartphones are not with them. Only $19.3 \%$ of the respondents answered as strongly disagree and disagree (see Fig 5). This finding suggests that although academic staffs can be considered as mature persons, they have been negatively affected by the smartphones use.

In order to investigate whether smartphone gives negative impacts to academic staffs in a workplace (RQ6), participants were asked to response to the statements stated in Table 5 with answer options of always, sometimes and never.

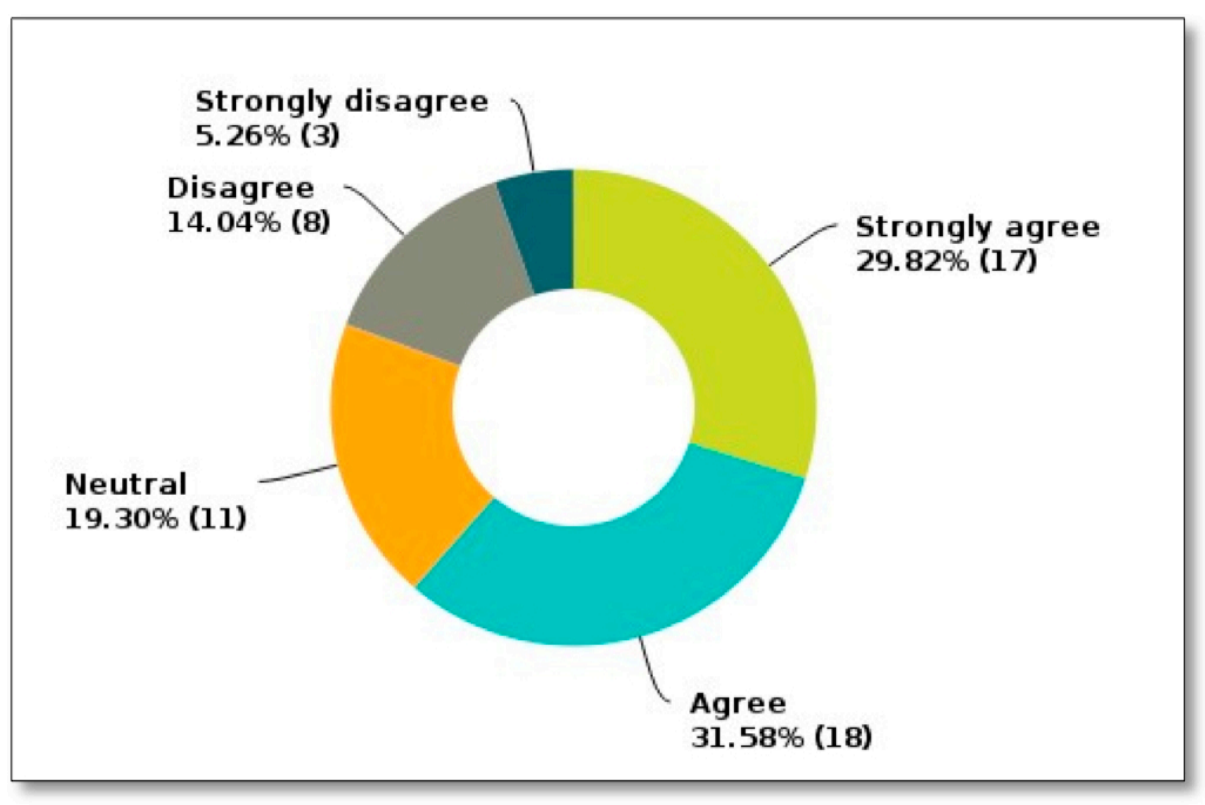

Fig. 5. Feelings of incompleteness without smartphones

Table 5. Negative impact of having smartphones in a workplace

\begin{tabular}{|l|c|c|c|}
\hline \multicolumn{1}{|c|}{ Questions } & \multicolumn{2}{c|}{ Response Percentage } \\
\cline { 2 - 4 } & Always & Sometimes & Never \\
\hline I tend to use my smartphone during a meeting at a workplace & 7.02 & 57.89 & 35.09 \\
\hline $\begin{array}{l}\text { I am checking my smartphone while talking to my co- worker at } \\
\text { the same time }\end{array}$ & 3.5 & 58.93 & 37.50 \\
\hline $\begin{array}{l}\text { I tend to postpone my job because I feel I can do my work at } \\
\text { anywhere and anytime using a smartphone }\end{array}$ & 5.36 & 57.14 & 37.50 \\
\hline
\end{tabular}


Result analysis reveals that less than $40 \%$ of academicians never use smartphones during a meeting at a workplace, never checking smartphone while talking to coworkers and never postponing job assignments. The results suggest smartphones are also able to divert academic staffs' focus on work.

Some researchers have claimed that smartphone has contributed to the imbalance attention between a personal life and a job (RQ7). To study this issue, we have asked our participants to answer to the survey "With a smartphone I am engaged to my job more than my family". Out of 66 participants, $46.13 \%$ disagree and strongly disagree with the statement. Only $26.78 \%$ has strongly agreed and disagreed. The result indicates smartphone has not been a major reason for imbalance attention between a family and a job. This result contradicts the finding reported in [13].

\section{Conclusion}

The resulting analysis for smartphone usage among academic staffs in the context of higher education reveals some interesting findings. Result analysis shows that a smartphone has been used as an alternative to a mobile computer, a digital camera, a watch, a messenger, and a digital storage. Among smartphone's applications, an email system has been the most useful smartphone apps for academic staffs. Findings also reveal that academic staffs cannot use a smartphone as a means to complete the job assignment faster. Carrying smartphones to a workplace has given some negative impacts to the job environment, where academic staffs are tended not to focus on their meetings or face to face communications with co-workers, as at the same time they are using their smartphones. Result analysis also showed that academic staffs have a very personal connected to their smartphone as only $7.27 \%$ of the respondents never put their smartphones besides their bed whenever they need to sleep. Furthermore, academic staffs are also negatively affected by the feelings of incompleteness without smartphones. In spite of negative effects, smartphones have been a very a great tool for supervising project's students and knowledge sharing.

\section{References}

[1] Qualman, E. Socialnomics: How Social Media Transforms the Way We Live and Do Business, 2009

[2] Guynn, J. "Facebook's WhatsApp hits 900 million users, aims for 1 billion". USA Today, September 4, 2015

[3] Rung A, Warnke F, Mattheos N. Investigating the Use of Smartphones for Learning Purposes by Australian Dental Students. Eysenbach G, ed.JMIR mHealth and uHealth. 2014;2(2):e20. https://doi.org/10.2196/mhealth.3120

[4] Alfawareh, H.M., and Jusoh, S. (2014). Smartphones usage among university students: Najran University case. International Journal of Academic Research, 6 (2). 321-326. https://doi.org/10.7813/2075-4124.2014/6-2/B.48

[5] Froese, A. D., Carpenter, C. N., Inman, D. A., Schooley, J. R., Barnes, R. B.,Brecht, P. W., \& Chacon, J. D. (2012). Effects of classroom cell phone use on expected and actual learning. College Student Journal. 46(2). 323- 332. 
[6] Tindell, D. R., \& Bohlander, R. W. (2012). The use and abuse of cell phones and text messaging in the classroom: A survey of college students. College Teaching, 60(1).1-9. Retrieved from http://www.tandfonline.com, https://doi.org/10.1080/87567555.2011.604802

[7] Elder, A.D. (2013). College students' cell phone use, beliefs, and effects on their Learning, College Student Journal, 47(4)pp, 585-592.

[8] Mtega WP, Bernard R, Msungu AC, Sanare R. Using mobile phones for teaching and learning purposes in higher learning institutions: The case of Sokoine University of Agriculture in Tanzania. InProceedings and report of the 5th UbuntuNet Alliance annual conference 2012 (pp. 118-129).

[9] Herrington, Jan, et al. "Using mobile technologies to develop new ways of teaching and learning." University of Wollongong, 2009. 1-14.

[10] Herrington, A. "Using a smartphone to create digital teaching episodes as resources in adult education." 2009.

[11] Hingorani, K.K., Woodard, D., \& Danesh, N.A. Exploring how smartphones supports students' lives. Issues in Information System,13(2) 2012, 33-40

[12] Oulasvirta A, Rattenbury T, Ma L, Raita E. Habits make smartphone use more pervasive. Personal and Ubiquitous Computing. 2012 Jan 1;16(1):105-14. https://doi.org/10.1007/s0 0779-011-0412-2

[13] Harris TR. The impact of smartphones on work-life balance (Doctoral dissertation, Middle Tennessee State University), 2014.

\section{$7 \quad$ Authors}

Hejab M. Al Fawareh is currently an assistant professor at Faculty of Computing and Information Technology at the Northern Border University, Saudi Arabia.

Hejab Al Fawareh was born in Jordan. He obtained his PhD in Information Technology with specialization of Artificial Intelligence from Universiti Utara Malaysia. He has published numerous research articles. His research interests include natural language processing, social networks, and text mining.

Shaidah Jusoh is currently an associate professor at Faculty of Computing and Information Technology at the Northern Border University, Saudi Arabia. Shaidah Jusoh was born in Malaysia. She obtained her Bachelor of Information Technology (1996) from Universiti Utara Malaysia, Master of Science in Computer Science (1998) and PhD in Engineering System and Computing from the University of Guelph (2006), Canada. She has been an active member of editorial board committees, reviewer committees and technical program committees of international journals and proceedings and publications. She has published numerous research articles. She has become a Member of IEEE since 2012.

Article submitted 25 July 2017. Published as resubmitted by the authors 13 September 2017. 